\title{
OPTIMASI PREDIKSI INFLASI DENGAN NEURAL NETWORK PADA TAHAP WINDOWING: ADAKAH PENGARUH PERBEDAAN WINDOW SIZE?
}

\author{
Rizchi Eka Wahyuni ${ }^{1)}$ \\ ${ }^{1}$ BPS Provinsi Jawa Tengah \\ email : rizchi@bps.go.id
}

\begin{abstract}
Abstrak
Inflasi adalah indikator yang penting dalam penentuan kebijakan pemerintah. Data inflasi dirilis oleh Badan Pusat Statistik (BPS) di setiap awal bulan. Jika data inflasi dapat diprediksi lebih awal, pemerintah bisa menerapkan kebijakan yang tepat. Backpropagation neural network adalah salah satu metode prediksi yang lazim digunakan. Dengan menggunakan data bulan-bulan sebelumnya, inflasi dapat diprediksi menggunakan metode neural network dengan menggunakan teknik sliding window yang juga disebut metode windowing. Windowing adalah pembentukan struktur dari data time series menjadi data cross sectional. Ukuran dari windowing akan mempengaruhi akurasi dari hasil prediksi. Pada penelitian ini, penulis melakukan percobaan dengan tiga window size yaitu 6, 12, dan 18 untuk melihat adakah perbedaan akurasi hasil dari beberapa window size tersebut. Hasil percobaan menyimpulkan bahwa window size 6 memiliki akurasi paling baik untuk memprediksi inflasi dengan RMSE 0,435 .
\end{abstract}

Keywords: backpropagation, prediksi, sliding window

\section{PENDAHULUAN}

Inflasi adalah salah satu indikator dalam penyusunan Anggaran Pendapatan dan Belanja Negara (APBN) [1][2]. Inflasi dirilis oleh Badan Pusat Statistik (BPS) satu bulan sekali yaitu di awal bulan. Data inflasi adalah salah satu data yang digunakan oleh pemerintah dalam pengambilan kebijakan[3][4][5]. Tulisan ini bertujuan untuk melakukan peramalan data inflasi dengan metode neural network. Masalah ini sangat penting karena dengan mengetahui lebih dini angka inflasi, maka pemerintah bisa merencanakan kebijakan-kebijakan yang akan berpengaruh terhadap kondisi perekonomian Indonesia.

Peramalan inflasi dapat dilakukan dengan berbagai metode di antaranya adalah extreme learning machine[6], support vector regression[7], exponential smoothing[8], fuzzy time series[9], multiple regression[10], ensembel[11], dan neural network[10],[12],[13]. Metode neural network sendiri adalah salah satu metode kecerdasan buatan yang banyak digunakan dalam peramalan termasuk dalam peramalan inflasi di dunia [14-15] dan beberapa penelitian yang pernah dilakukan di Indonesia [10],[12],[13]. Tentu masing-masing metode tersebut memiliki perbedaan, baik kelebihan maupun kekurangan. Penelitian yang menggunakan metode neural network sendiri memiliki beberapa kelebihan di antaranya metode ini sesuai digunakan untuk melakukan prediksi data nonlinier[16]. Metode neural network dipilih dalam penelitian ini dikarenakan data inflasi adalah data nonlinier, sehingga penulis menduga akan akurat hasilnya jika inflasi diprediksi menggunakan metode ini. Selain itu, sebagian besar model prediksi inflasi dibuat berdasarkan variabel-variabel penyusunnya. Dalam penelitian ini model prediksi dibuat berdasarkan data pada tahuntahun sebelumnya sehingga topik ini menarik untuk dibahas.

Sebelum diolah dengan algoritma neural network, maka data harus melalui tahap preprocessing. Tahap preprocessing adalah tahap penyiapan data sebelum data tersebut diolah dengan algoritma yang ditentukan. Salah satu tahap preprocessing yang harus dilakukan untuk peramalan data time series adalah windowing [17]. Sliding window algorithm adalah proses transformasi data time series menjadi data cross sectional. Berdasarkan penelitian sebelumnya [17][18], disebutkan bahwa window size mempunyai peranan yang penting dalam data time series. Window size dimulai dari nilai yang lebih kecil dan terus ditingkatkan hingga mencapai titik tertentu.

Sepanjang pengetahuan penulis, studi mengenai masalah ini masih terbatas. Beberapa studi sebelumnya pernah dilakukan oleh Rhee 
M. Kill, Hota dan Shuja-ur-Rehman Baig [1921]. Hasil studi tersebut menunjukkan bahwa window size berpengaruh terhadap akurasi suatu metode peramalan. Namun sampai saat ini penulis belum menemukan penelitian tentang window size optimal dalam penerapan peramalan data inflasi. Kajian ini dibatasi pada pemilihan window size optimal untuk prediksi data inflasi berdasarkan nilai root mean square error (RMSE). RMSE adalah parameter yang digunakan untuk melihat akurasi suatu metode peramalan [22]. Semakin kecil RMSE maka semakin akurat metode prediksi yang digunakan.

\section{METODE PENELITIAN}

Pada penelitian ini kami mengusulkan tahapan penelitian pada Gambar 1 .

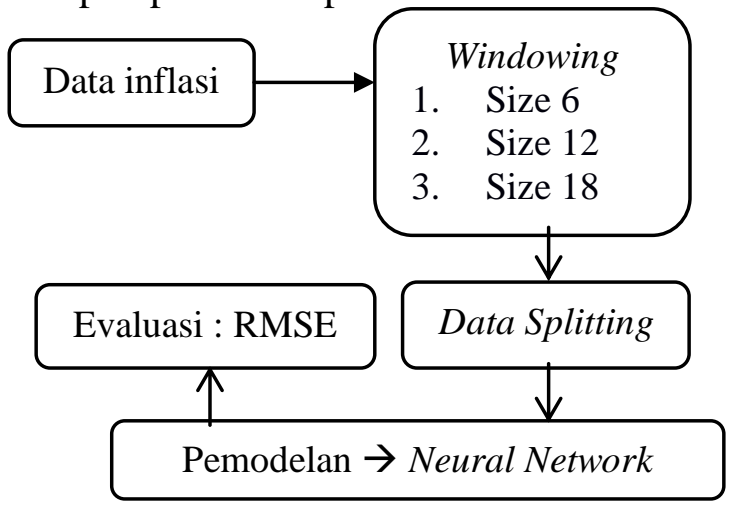

\section{Data}

Dataset yang digunakan dalam penelitian ini adalah data inflasi yang dirilis oleh Badan Pusat Statistik (BPS). Periode data adalah Januari 1999 sampai dengan Desember 2019. Data disajikan pada Tabel 1.

\section{Sliding Window Algorithm (SWA)}

Sliding Window atau windowing adalah pembentukan struktur dari data time series yang tersedia. Ukuran dari window dan segmen dilakukan perubahan untuk memperoleh error yang terkecil. Dari Gambar 2 dapat diilustrasikan contoh dari sliding window size 5. Angka 1 sampai 10 adalah unit observasi dari data time series. Misalkan angka 1 menggambarkan data pada bulan ke-1, angka 2 menggambarkan data pada bulan ke-2 dan seterusnya. Window pertama dimulai dari data ke-1 sampai dengan ke-5 yang digunakan untuk memprediksi data ke-6. Segmen kedua dimulai dari data ke-2 sampai dengan data ke-6 yang digunakan untuk memprediksi data ke-7. Proses ini terus dilanjutkan sampai dengan seluruh data hasil observasi habis tersegmentasi [22].

Gambar 1. Desain Penelitian

Tabel 1. Data inflasi Indonesia periode Januari 1999 sampai dengan Desember 2019

\begin{tabular}{|c|c|c|c|c|c|c|c|c|c|c|c|c|}
\hline Tahun & Januari & Februari & Mar & April & Mei & Juni & Juli & Agust & Sept & Okt & Nov & Des \\
\hline 2019 & 0.32 & -0.08 & 0.11 & 0.44 & 0.68 & 0.55 & 0.31 & 0.12 & -0.27 & 0.02 & 0.14 & 0.34 \\
\hline 2018 & 0.62 & 0.17 & 0.20 & 0.10 & 0.21 & 0.59 & 0.28 & -0.05 & -0.18 & 0.28 & 0.27 & 0.62 \\
\hline 2017 & 0.97 & 0.23 & -0.02 & 0.09 & 0.39 & 0.69 & 0.22 & -0.07 & 0.13 & 0.01 & 0.20 & 0.71 \\
\hline 2016 & 0.51 & -0.09 & 0.19 & -0.45 & 0.24 & 0.66 & 0.69 & -0.02 & 0.22 & 0.14 & 0.47 & 0.42 \\
\hline 2015 & -0.24 & -0.36 & 0.17 & 0.36 & 0.50 & 0.54 & 0.93 & 0.39 & -0.05 & -0.08 & 0.21 & 0.96 \\
\hline 2014 & 1.07 & 0.26 & 0.08 & -0.02 & 0.16 & 0.43 & 0.93 & 0.47 & 0.27 & 0.47 & 1.50 & 2.46 \\
\hline 2013 & 1.03 & 0.75 & 0.63 & -0.10 & -0.03 & 1.03 & 3.29 & 1.12 & -0.35 & 0.09 & 0.12 & 0.55 \\
\hline 2012 & 0.76 & 0.05 & 0.07 & 0.21 & 0.07 & 0.62 & 0.70 & 0.95 & 0.01 & 0.16 & 0.07 & 0.54 \\
\hline 2011 & 0.89 & 0.13 & -0.32 & -0.31 & 0.12 & 0.55 & 0.67 & 0.93 & 0.27 & -0.12 & 0.34 & 0.57 \\
\hline 2010 & 0.84 & -0.08 & -0.14 & 0.15 & 0.29 & 0.97 & 1.57 & 0.76 & 0.44 & 0.06 & 0.60 & 0.92 \\
\hline 2009 & -0.07 & 0.21 & 0.22 & -0.31 & 0.04 & 0.11 & 0.45 & 0.56 & 1.05 & 0.19 & -0.03 & 0.33 \\
\hline 2008 & 1.77 & 0.65 & 0.95 & 0.57 & 1.41 & 2.46 & 1.37 & 0.51 & 0.97 & 0.45 & 0.12 & -0.04 \\
\hline 2007 & 1.04 & 0.62 & 0.24 & -0.16 & 0.10 & 0.23 & 0.72 & 0.75 & 0.80 & 0.79 & 0.18 & 1.10 \\
\hline 2006 & 1.36 & 0.58 & 0.03 & 0.05 & 0.37 & 0.45 & 0.45 & 0.33 & 0.38 & 0.86 & 0.34 & 1.21 \\
\hline 2005 & 1.43 & -0.17 & 1.91 & 0.34 & 0.21 & 0.50 & 0.78 & 0.55 & 0.69 & 8.70 & 1.31 & -0.04 \\
\hline 2004 & 0.57 & -0.02 & 0.36 & 0.97 & 0.88 & 0.48 & 0.39 & 0.09 & 0.02 & 0.56 & 0.89 & 1.04 \\
\hline 2003 & 0.80 & 0.20 & -0.23 & 0.15 & 0.21 & 0.09 & 0.03 & 0.84 & 0.36 & 0.55 & 1.01 & 0.94 \\
\hline 2002 & 1.99 & 1.50 & -0.02 & -0.24 & 0.80 & 0.36 & 0.82 & 0.29 & 0.53 & 0.54 & 1.85 & 1.20 \\
\hline 2001 & 0.33 & 0.87 & 0.89 & 0.46 & 1.13 & 1.67 & 2.12 & -0.21 & 0.64 & 0.68 & 1.71 & 1.62 \\
\hline 2000 & 1.32 & 0.07 & -0.45 & 0.56 & 0.84 & 0.50 & 1.28 & 0.51 & -0.06 & 1.16 & 1.32 & 1.94 \\
\hline 1999 & 2.97 & 1.26 & -0.18 & -0.68 & -0.28 & -0.34 & -1.05 & -0.93 & -0.68 & 0.06 & 0.25 & 1.73 \\
\hline
\end{tabular}

Sumber : Badan Pusat Statistik 


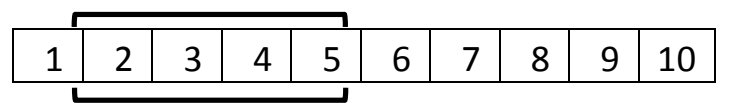

\begin{tabular}{|l|l|l|l|l|l|l|l|l|l|}
\hline 1 & 2 & 3 & 4 & 5 & 6 & 7 & 8 & 9 & 10 \\
\hline
\end{tabular}

Gambar 2. Proses dari sliding window

Tujuan dari sliding window adalah mengurangi error aproksimasi (misalnya jarak Euclidean atau jarak vertikal antara aproksimasi yang sebenarnya dengan time series). Kesalahan batas ini diwakili oleh berapa parameter yang digunakan dalam time series [23].

Pada penelitian ini akan dilakukan percobaan terhadap window size optimal. Segmentasi data inflasi akan dibuat menjadi tiga window size yaitu window size 6, 12, dan 18. Selanjutnya, data hasil segmentasi akan dimodelkan dengan menggunakan algoritma neural network.

\section{Data Splitting}

Pada setiap penelitian dilakukan data splitting untuk menentukan data yang akan digunakan untuk training dan testing. Dengan melakukan data splitting, akurasi dapat diukur dari model yang telah dihasilkan.

Ada beberapa metode data splitting. Metode yang paling umum digunakan adalah metode $\mathrm{k}$ fold cross validation. Namun berdasarkan penelitian sebelumnya [24], metode yang paling tepat untuk menghindari over fitting adalah metode holdout cross validation. Penelitian lain [25] menjelaskan bahwa jumlah dataset sebanyak 100 dataset, seperti yang digunakan dalam penelitian ini, termasuk dataset yang kecil untuk neural network. Pasini [26] mengusulkan suatu metode splitting leave one out cross validation untuk mengatasi permasalahan penggunaan neural network pada dataset yang kecil. Oleh karena itu, pada penelitian ini digunakan metode splitting leave one out cross validation. Metode leave one out cross validation dilakukan dengan melakukan iterasi sebanyak baris data untuk menggunakan n-1 data sebagai data training dan 1 data sebagai data testing.

Jurnal Ilmiah "Technologia”

\section{Neural Network}

Neural Network (NN) adalah salah satu metode dalam kecerdasan buatan yang cara kerjanya menirukan cara kerja otak manusia dalam menyelesaikan suatu masalah. Neural network mengidentifikasi kegiatan berdasarkan data masa lalu. Neural network mempelajari data masa lalu untuk memberi keputusan terhadap data yang akan datang [27].

Neural network merupakan bentuk arsitektur yang didistribusikan secara paralel dengan jumlah node yang banyak dan hubungan antar node. Node ini biasanya disebut sebagai neuron. Hubungan satu neuron dengan neuron lain memiliki nilai disebut sebagai bobot. Setiap neuron memiliki nilai yang terkait sebagai nilai aktivasi neuron [27].

Metode backpropagation merupakan salah satu metode neural network yang lazim digunakan[10][12][13]. Pada jaringan diberikan sepasang data yang terdiri atas data masukan dan data yang diinginkan. Ketika data dimasukkan dalam arsitektur jaringan, nilai bobot diubah untuk memperkecil perbedaan antara pola keluaran dan pola yang diinginkan. Latihan ini dilakukan berulang-ulang sehingga perbedaan yang dihasilkan berada pada titik minimum. Pada penelitian ini, untuk menjalankan algoritma neural network digunakan aplikasi rapidminer.

\section{HASIL DAN PEMBAHASAN}

Grafik perbandingan nilai inflasi riil dan prediksi dari tiga window size disajikan pada gambar berikut:

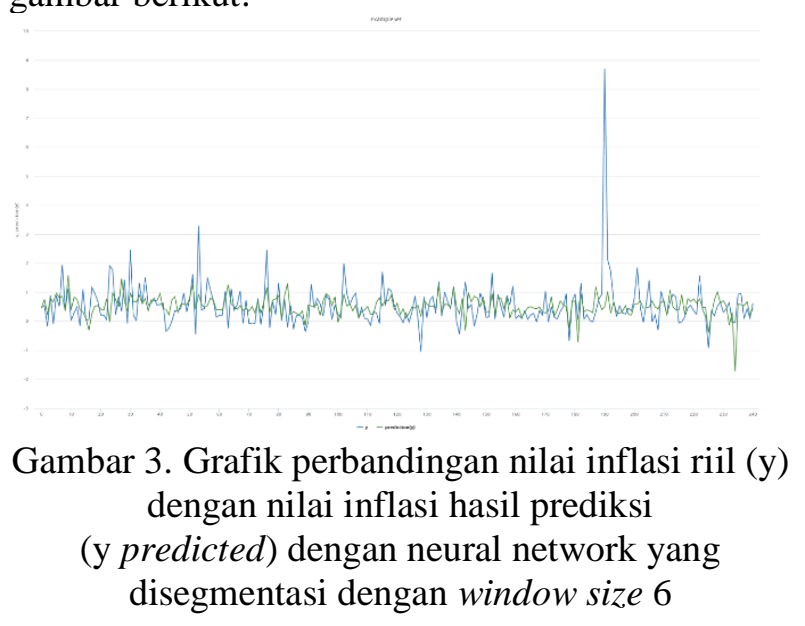




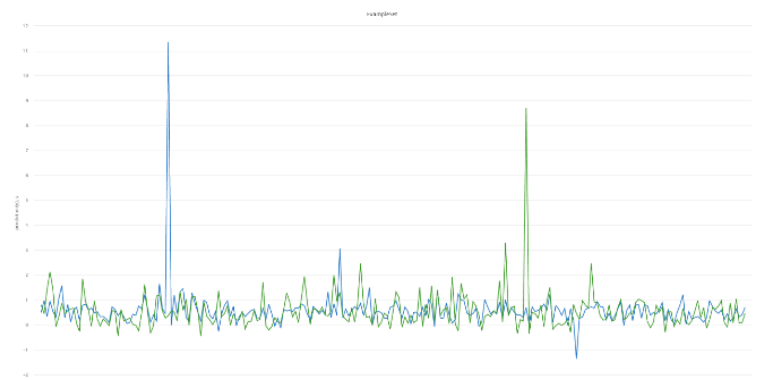

Gambar 4. Grafik perbandingan nilai inflasi riil (y) dengan nilai inflasi hasil prediksi (y predicted) dengan neural network yang disegmentasi dengan window size 12

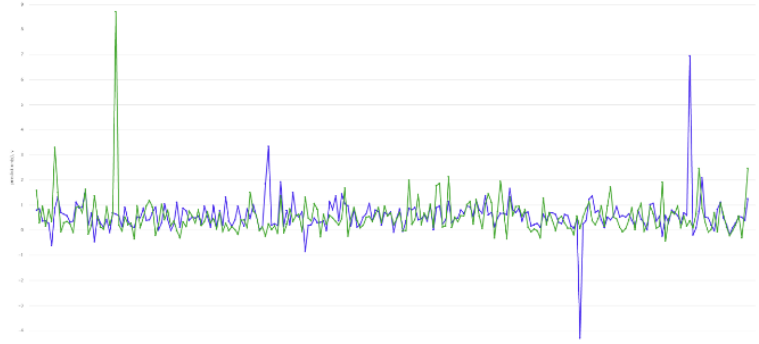

Gambar 5. Grafik perbandingan nilai inflasi riil (y) dengan nilai inflasi hasil prediksi (y predicted) dengan neural network yang disegmentasi dengan window size 18

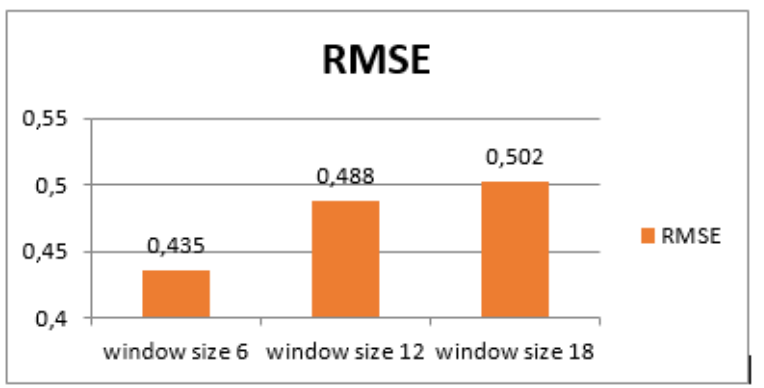

Gambar 6. Grafik perbandingan RMSE model prediksi inflasi dengan neural network berdasarkan beberapa window size

Gambar 3, Gambar 4, dan Gambar 5 adalah grafik perbandingan antara nilai y actual dengan nilai y hasil prediksi. Gambar 6 adalah grafik perbandingan RMSE dari ketiga model. Dari grafik pada Gambar 6 dapat disimpulkan bahwa prediksi inflasi dengan window size 6 memiliki RMSE paling kecil. Sehingga untuk permalan data inflasi dengan metode neural network, window size 6 adalah ukuran splitting yang paling optimal.
Hal tersebut sejalan dengan penelitian Hota[20], dimana prediksi dengan sliding window 10 memiliki nilai RMSE lebih kecil daripada RMSE prediksi dengan sliding window 15 dan 20. Namun pada penelitian Hota[20], ternyata nilai RMSE sliding window size 5 lebih besar dari RMSE sliding window 10. Dharmawati [28] dalam penelitiannya menyimpulkan bahwa dalam memprediksi nilai tukar rupiah, diperoleh bahwa window size 4 memiliki nilai RMSE paling kecil dibandingkan dengan window size 1, 2, 3, 5, 6, 7, 8,9 , dan 10. Nooriansyah[29] dalam penelitiannya menyimpulkan bahwa window size 3 lebih optimal dibandingkan dengan window size 1 dan window size 5 dalam prediksi tinggi gelombang. Penelitian lain yang dilakukan oleh Radjabaycolle[30], dimana hasil prediksi bandwith dengan metode elman recurrent neural network menunjukkan bahwa window size 8 lebih optimum dibandingkan dengan window size 4, 6, 10, 12, 14, dan 16.

Oleh karena itu, dari penelitian ini perlu dilakukan penelitian lanjutan dengan menerapkan sliding window yang lebih kecil lagi, misalnya 3 atau 4 untuk melihat nilai RMSE model prediksi. Hal tersebut karena menurut opini penulis, nilai window size yang semakin kecil akan menghasilkan RMSE yang semakin kecil. Namun hal tersebut akan berhenti pada satu titik dimana window size menghasilkan RMSE minimum [19][27][28][29].

\section{KESIMPULAN}

Untuk melakukan peramalan inflasi dengan neural network, window size yang paling optimal adalah window size 6 dibandingkan dengan window size 12 dan window size 18. Namun penelitian lebih lanjut perlu dilakukan dengan window size yang lain. Penelitian lanjutan juga bisa dilakukan dengan menggunakan metode prediksi lain, seperti regression atau support vector machine. Selain itu, dapat pula ditambahkan metode optimasi seperti particle swarm optimization (PSO) untuk meningkatkan akurasi prediksi data inflasi. 


\section{REFERENSI}

[1] Kementrian Keuangan. 2021. Informasi APBN 2021 Percepatan pemulihan Ekonomi dan dan Penguatan Reformasi. Kementrian Keuangan. Jakarta.

[2] Kementrian Keuangan. 2021. Kerangka Ekonomi Makro dan Pokok-pokok Kebijakan Fiskal Tahun 2021. Kementrian Keuangan. Jakarta.

[3] Imansyah, MH. 2007. Kebijakan Inflation Targeting: Antisipasi Krisis Nilai Tukar. Jurnal Ekonomi dan Studi Pembangunan Volume 8 Nomor 2 Oktober 2007:162-170.

[4] Al Amin, E.M.A. 2020. Kebijakan Pemerintah Mempertahankan Bi7-Day Reverse Repo Rate Sebesar 4,50\%", IQTISHADUNA: Jurnal Ilmiah Ekonomi Kita Vol.9, No.2: 125-135.

[5] Khoeruloh, A.K, et.al. 2020. Inflasi Dan Bi 7Day Repo Rate: Faktor Penentu Profitabilitas Bank Umum Syariah Di Indonesia. Jurnal Ekonomi Syariah dan Bisnis E-ISSN: 26215012 P-ISSN 2655-822X.

[6] A. N. Alfiyatin, W. F. Mahmudy, C. F. Ananda, dan Y. P. Anggodo. 2019. Penerapan Extreme Learning Machine (ELM) untuk Peramalan Laju Inflasi di Indonesia. $J$. Teknol. Inf. dan Ilmu Komput vol. 6, no. 2, p. 179.

[7] Husnul Khatimi, Muhammad Alkaff, dan Dewi Rizqia Najipah. 2017. Penerapan Support Vector Regression (SVR) Untuk Peramalan Inflasi Bulanan Nasional. $J$. Teknol. Inf. Univ. Lambung Mangkurat vol. 2, no. 2, pp. 59-64.

[8] A. E. Armi, A. H. Kridalaksana, dan Z. Arifin. 2019. Peramalan Angka Inflasi Kota Samarinda Menggunakan Metode Double Exponential Smoothing (Studi Kasus : Badan Pusat Statistik Kota Samarinda). Inform. Mulawarman J. Ilm. Ilmu Komput. vol. 14 no. 1, p. 21.

[9] Udin, AC dan Jatipaningrum, MT. 2020. Peramalan Inflasi Di Indonesia Menggunakan Metode Fuzzy Time Series Basedaveragedan Fuzzy Time Series Saxena-Easo. Jurnal Statistika Industri dan Komputasi Volume 05 No. 2 Juli pp. 1-10.

[10] A. Amrin. 2016. Analisa Komparasi Neural Network Backpropagation Dan Multiple
Linear Regression Untuk Peramalan Tingkat Inflasi. Jurnal Teknik Komputer vol. II no. 2, pp. 1-6.

[11] M. Silfiani and I. Pendahuluan. 2012. Aplikasi Metode Ensembel untuk Peramalan Inflasi di Indonesia. Jurnal Sains Dan Seni ITS Vol. 1 No. 1.

[12] A. Amrin. 2014. Peramalan Tingkat Inflasi Indonesia Menggunakan Neural Network Backpropagation Berbasis Metode Time Series. Jurnal Techno Nusa Mandiri Vol. XI No. 2.

[13] K. Wong, A. P. Wibawa, H. S. Pakpahan, A. Prafanto, and H. J. Setyadi. 2019. Prediksi Tingkat Inflasi Dengan Menggunakan Metode Backpropagation Neural Network. Sains, Apl. Komputasi dan Teknol. Inf., vol. 1, no. 2, p. 8.

[14] Nakamura, Emi. 2005. Inflation Forecasting using neural network. Economics letters 373378.

[15] Thakur, Gour SMm et.al. 2016. Artificial Neural Network Based Modle for forecasting of inflation in India. Fuzzy Information and Engineering 8: 87-100.

[16] Tu, Jack V. 1996. Advantages and Disadvantages of Using Artificial Neural Networks versus Logistic Regression for Predicting Medical Outcomes. J Clin Epidemol Vol 49, No. 11, pp. 1223-1231.

[17] Han, J. and M. Kamber. 2001. Data Mining:Concepts and Techniques. Morgan Kaufmann. USA.

[18] Frank, R.J, et.al. 2001. Time Series Prediction and Neural Network. Journal of Intelligent and Robotic Systems 31: 91-103.

[19] M. Kil, Rhee, et.al. 1997. Optimum Window Size for Time Series Prediction. Proceedings - 19th International Conference - IEEE/EMBS Oct. 30 - Nov. 2, 1997 Chicago, IL. USA.

[20] Hota, H.S., et.al. 2017. Time Series Data Prediction Using Sliding Window Based RBF Neural Network. International Journal of Computational Intelligence Research ISSN 0973-1873 Volume 13 Number 5 pp. 11451156.

[21] Baig, S, et.al. 2019. Adaptive Sliding Windows for Improved Estimation of Data Center Resource Utilization. Future Generation Computer Systems. 
[22] Zhuo Chen and Yuhong Yang. 2004. Assessing Forecast Accuracy Measures .Iowa State University.

[23] Yahmed,Y.B., Bakar.A.a., Razak Hamdan,A., Ahmed, A., \& Abdullah, S.M.S. 2015. Adaptive sliding window algorithm for weather data segmentation. Journal of Theoretical and Applied Information Technology 80(2), 322-333.

[24] Reitermanova, Z. 2010. Data Splitting", WDS'10 Proceedings of Contributed Paper Part 1, 31-36.

[25] Shaikhina, Torgyn, Natalia A Khovanova. 2017. Handling limited datasets with neural networks in medicalapplications: A smalldata approach". Artificial Intelligence in Medicine 75 (2017) 51-63.

[26] Pasini, A. 2015. Artificial Neural Networks for Small Dataset Analysis. Journal of Thoracic Disease. 2015.
[27] Hermawan, A. 2006. Jaringan Saraf Tiruan, Teori, dan Aplikasi. Penerbit Andi, Yogyakarta.

[28] Dharmawati, Adani. 2018. Neural Network Berbasis PSO Dalam Prediksi Nilai Tukar Rupiah Terhadap Euro. Technologia Vol 9, No.1.

[29] Nooriansyah, Subhan,et.al. 2018. Analisis Kinerja Metode Artificial Neural Network Dan Support Vector Regression Untuk Prediksi Significant Wave Height. SCAN VOL. XIII NOMOR 1.

[30] Radjabaycolle, Jefri dan Pulungan, Reza. 2016. Prediksi Penggunaan Bandwidth Menggunakan Elman Recurrent Neural Network. Barekeng Jurnal Ilmu Matematika dan Terapan | Volume 10 Nomor 2 | Hal. 127 -135 . 